\title{
JUROS, CÂMBIO E AS IMPERFEIÇÕES DO CANAL DO CRÉDITO*
}

\author{
Dionísio Dias Carneiro ${ }^{\S}$ \\ Felipe Monteiro Salles ${ }^{\alpha}$ \\ Thomas Yen Hon $\mathrm{Wu}^{\dagger}$
}

\begin{abstract}
RESUMO
O objetivo deste artigo é analisar o papel do crédito como mecanismo de transmissão da política monetária. Inicialmente apresentamos uma descrição teórica do canal de crédito de uma economia estilizada e quantificamos os efeitos do canal de crédito na economia brasileira via estimação de uma equação de demanda por crédito. Examinamos, então, o canal de crédito como transmissor dos choques de demanda, via balanço das empresas, atuando como um "multiplicador financeiro" desses choques. Por fim, apresentamos evidência empírica da atuação deste "multiplicador financeiro" na economia brasileira por meio de movimentos da taxa de câmbio, o que permite dar uma explicação para os efeitos prolongados de crises cambiais sobre o crescimento.
\end{abstract}

Palavras-chave: canal de crédito, multiplicador financeiro, taxa de câmbio.

\begin{abstract}
The objective of this paper is to analyze the role of credit as a monetary policy transmission mechanism. First we present a theoretical description of the credit channel of a stylized economy and then quantify the effects of the credit channel on the Brazilian economy by estimating a credit demand equation. We, then, focus on the credit channel as a transmitter of demand shocks via firms' balance sheets, functioning as "financial multiplier" of those shocks. Concluding, we analyze the empirical evidence of that "financial multiplier" through which movements in the exchange rate impact the Brazilian economy, a possible explanation for lasting effects of exchange rate crises on economic growth.
\end{abstract}

Key words: credit channel, financial multiplier, exchange rates.

JEL classification: E52, F31, F41.

\footnotetext{
* Os autores agradecem a assistência de Renata T. Assis, Eugênia Vilela, Claudia Sussekind e Marcelo Carvalho na preparação deste trabalho. Os erros e omissões são unicamente de responsabilidade dos autores.

$\S$ Professor do Departamento de Economia da PUC-Rio e Diretor do Instituto de Estudos de Política Econômica (IEPE/CdG) E-mail: dionisio@galanto.com.br.

a Doutorando do Departamento de Economia da London School of Economics. E-mail: f.m.salles@1se.ac.uk.

$\dagger$ Doutorando do Departamento de Economia da Princeton University e Membro Associado do Instituto de Estudos de Política Econômica (IEPE/CdG).E-mail: thomas@iepecdg.com.

Endereço para contato: Av. Ataulfo de Paiva, 1235 - sala 103 - leblon - Rio de Janeiro - RJ - CEP 22440-034.
}

Recebido em setembro de 2004. Aceito em junho de 2005. 


\section{INTRODUÇÃO}

A Política Monetária pode afetar o nível de atividade econômica, e o mecanismo mais tradicional é via despesa de investimento da economia, que é um dos componentes da demanda agregada. O que é objeto de controvérsia é a duração e a relevância destes efeitos. Para os adeptos dos "ciclos reais", na tradição de King e Plosser (1984), o sistema bancário responde aos estímulos do ciclo, e a correlação entre renda real e moeda revela antes a causação inversa e não a capacidade das autoridades monetárias. Desde a tradição keynesiana, o canal de crédito é um mecanismo simples para explicar os efeitos dos juros sobre o custo de captação das firmas. Apesar de uma explicação com alto apelo didático, essa abordagem não fornece, entretanto, uma maneira simples para compatibilizar a modelagem teórica com evidências empíricas minimamente convincentes. ${ }^{1}$ No caso brasileiro, existem fatores adicionais para justificar um certo ceticismo nas opiniões usualmente transmitidas pela imprensa quanto à eficácia do mecanismo de transmissão via mercado de crédito (usa-se, em geral, o aperto de crédito como sinônimo de aperto monetário). Uma razão para essas dificuldades adicionais é resultado da alta inflação experimentada até meados dos anos noventa, que virtualmente paralisou o mercado de crédito bancário, dada a grande variância das taxas de juros reais que decorreram da elevada variabilidade da taxa de inflação. Outra, é que depois do Plano Real, quando certamente diminuiu a variância da inflação (inflação esta que até o ano passado havia se tornado bem mais previsível), a variância das taxas reais de juros permaneceu elevada. Isso ocorreu em razão do uso da política monetária para se evitar que os sucessivos choques de oferta desorganizassem o esforço de construção de um ambiente de baixa inflação, em uma economia que mal saía de uma longa experiência de alta inflação e vários experimentos fracassados de estabilização. Como resultado prático, a proporção de crédito privado com relação ao Produto Interno Bruto se manteve praticamente constante ao longo de todo o período do Plano Real, como pode ser visto na Figura 1.

O objetivo deste artigo é analisar o canal de crédito na economia brasileira. Este objetivo será alcançado em 2 etapas. Na primeira etapa (seção 2), examinamos um dos canais pelos quais o nível de crédito tem impacto sobre o nível de atividade, ou seja, por meio do encarecimento do financiamento disponível aos investimentos das firmas. Procuramos, então, nesta primeira etapa, quantificar os efeitos do canal de crédito por meio da estimação de uma equação de demanda por crédito. Apresentamos uma descrição teórica do canal de crédito de uma economia estilizada. O objetivo é identificar as variáveis instrumentais necessárias para se resolver problemas de endogeneidade que serão observados.

1 Vejam-se as dificuldades em Taylor (1995) e Bernanke e Gertler (1995) sobre o papel da evidência de efeitos das taxas de juros fixadas pelas autoridades monetárias sobre o custo de capital. 
Figura 1 - Proporção crédito/PIB (em valores correntes)

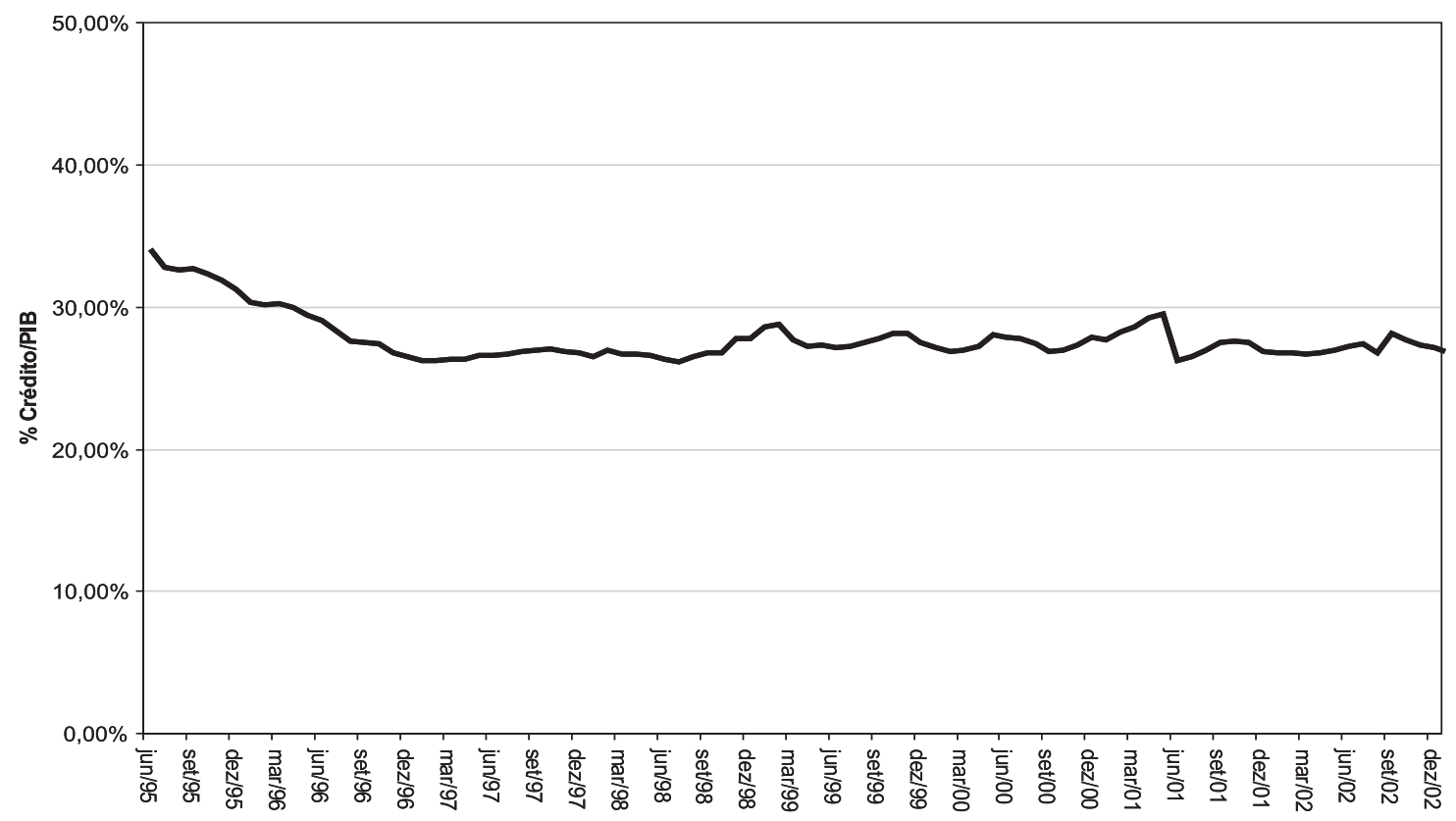

Fonte: IBGE e Banco Central do Brasil.

Em uma segunda etapa (seção 3) examinamos o canal de crédito como canal de transmissão dos choques de demanda, via balanço das empresas. A exigência de garantias, ou colateral, resulta de uma imperfeição do mercado de crédito cuja relação com os choques sobre a demanda agregada é explorada conceitualmente. Em primeiro lugar, discutimos como um problema de incentivo na relação credor-devedor gera essa imperfeição no mercado de crédito. Em segundo lugar, descrevemos, de forma detalhada, como essa imperfeição atua como um "multiplicador financeiro" dos choques macroeconômicos, amplificando não apenas a magnitude, mas também a persistência dos efeitos de um choque temporário negativo. Por fim, em terceiro lugar, apresentamos evidência empírica da atuação deste "multiplicador financeiro" na economia brasileira, por meio de movimentos da taxa de câmbio. Na medida em que diversas firmas possuem passivo em dólar, uma depreciação (justificada ou não pelos fundamentos econômicos) na taxa de câmbio eleva o passivo dessas empresas, enfraquecendo seus balanços, afetando o crédito e, conseqüentemente, o investimento e a demanda agregada.

\section{VERSÃO ESTILIZADA DO CANAL DE CRÉDITO}

Procuramos, nesta seção, quantificar os efeitos do canal de crédito via estimação de uma equação de demanda por crédito. A primeira subseção apresenta uma descrição teórica do canal de crédito de uma economia estilizada. O objetivo seria, assim, identificar variáveis instrumentais necessárias para se resolver problemas de endogeneidade, que serão observados na segunda subseção. A terceira subseção apresenta os resultados econométricos. 


\subsection{Descrição estilizada do canal de crédito}

Da mesma forma que as unidades familiares costumam buscar empréstimos para financiar as necessidades de gastos que superam suas rendas correntes, poucas empresas possuem um patrimônio suficientemente líquido para financiar todos os seus projetos de investimento. Grande parte do estoque de capital necessário para a realização de um empreendimento é adquirida por meio de algum mecanismo de crédito, o que implica a presença de um custo de captação, o qual, se não for a própria taxa de juros básica da economia, estará positivamente relacionado a ela (por exemplo, mediante um prêmio de risco).

A oferta de crédito reage, assim, (1) positivamente à taxa de juros básica da Autoridade Monetária, pois quanto maior a taxa de juros, maior é a rentabilidade oferecida aos depositantes e menor é a propensão a consumir, na medida em que há um maior incentivo à postergação do consumo corrente a fim de se permitir um maior consumo futuro, segundo a hipótese do ciclo de vida de Modigliani e Brumberg (1954). Este é o canal captado por uma Curva IS tradicional. A oferta de crédito reage, ainda, (2) positivamente à renda agregada. Um aumento temporário na renda é poupado pelas famílias, a fim de garantir um padrão de vida mínimo em períodos em que a renda venha a sofrer choques negativos, de acordo com a hipótese da renda permanente introduzida por Friedman (1957).

Ao mercado financeiro cabe, por excelência, o papel de intermediário entre a oferta e a demanda por crédito, atuando na captação de poupança das famílias, em uma ponta, e provendo financiamento para o investimento privado, na outra. Um dos principais serviços providos pelo mercado financeiro como um todo é avaliar o risco de crédito dos agentes que demandam empréstimos, de tal maneira que agentes que apresentem um risco de default muito alto não consigam captar financiamento. Dessa forma, a oferta de crédito disponível para as firmas depende (3) negativamente do risco de inadimplência.

Apesar de estarmos interessados na demanda por crédito do setor privado doméstico, uma instituição financeira doméstica pode estar captando recursos externos e os repassando no mercado doméstico. Tendo em vista essa possibilidade, variáveis associadas às condições de liquidez dos mercados internacionais também afetam a oferta de crédito doméstica: devemos esperar que a oferta de crédito apresente uma relação negativa com o prêmio de risco-país (4) e a taxa de juros internacional (5).

Por fim, as firmas demandam o crédito dos bancos para financiarem o estoque de capital necessário à realização de seus projetos. Considerando-se agentes racionais e firmas maximizadoras de lucro, dado que o custo de oportunidade de uma unidade marginal do estoque de capital é dado pela taxa de juros, uma condição necessária para a maximização dos lucros é que a produtividade marginal do capital seja igual ao seu custo de oportunidade, a taxa de juros. Como a produtividade marginal dos fatores de produção é decrescente, uma taxa de juros menor implica um estoque de capital ótimo mais elevado. Para adquirir um aumento no estoque de capital a firma demanda mais crédito.

Na prática, essa distinção entre consumidores, bancos e firmas nem sempre é muito clara. Porém, essa distinção possui a vantagem de explicitar o papel de certas variáveis macroeconômicas nos mecanismos de crédito. Em particular, os papéis da renda agregada, da taxa de juros e da inadimplência. Como veremos na próxima subseção, o papel dessas variáveis será essencial para se encontrar a solução para alguns problemas econométricos envolvidos na estimação do canal do crédito. 


\subsection{Problemas econométricos: endogeneidade}

Estamos interessados na relação entre o crédito e a taxa de juros, do ponto de vista da demanda por financiamento das firmas. Conforme comentado anteriormente, a demanda por financiamento é maior quanto maior for o nível de investimento das firmas. Dessa forma, podemos captar o efeito da Política Monetária sobre o nível de investimento das firmas por meio do canal do crédito.

Porém, existe um problema ao se estimar diretamente uma série de crédito na taxa de juros real. A série observada de crédito utilizada mede o total de crédito (considerado de risco normal) do sistema financeiro privado ao setor privado em milhões de reais (a fonte é o Banco Central do Brasil). Interpretando o crédito como um bem e a taxa de juros real como o "preço" desse bem, não podemos distinguir se o coeficiente obtido dessa regressão representa uma elasticidade-preço da demanda ou da oferta. Este é o exemplo clássico de endogeneidade que dificulta a identificação das relações. Uma regressão de uma série de preço observado em uma série de quantidade observada representa uma sucessão de pontos de equilíbrios ao longo do tempo à medida que diversos choques de oferta e demanda vão deslocando as duas curvas. O coeficiente estimado de uma regressão da quantidade no preço não possui significado econômico.

Como, então, estimar a nossa curva de demanda por crédito? A solução consiste em utilizar variáveis instrumentais. A intuição desta solução é bastante simples. Se pudéssemos observar alguma variável que deslocasse apenas a posição da curva de oferta ao longo do tempo, e não alterasse a posição da curva de demanda, poderíamos utilizá-la para "traçar" a inclinação da curva de demanda, isto é, para estimar a elasticidade-preço da demanda. ${ }^{2}$ A Figura 2, que é freqüente nos livros-textos de econometria, ilustra esta idéia.

Figura 2 - Deslocando a oferta para se estimar a demanda

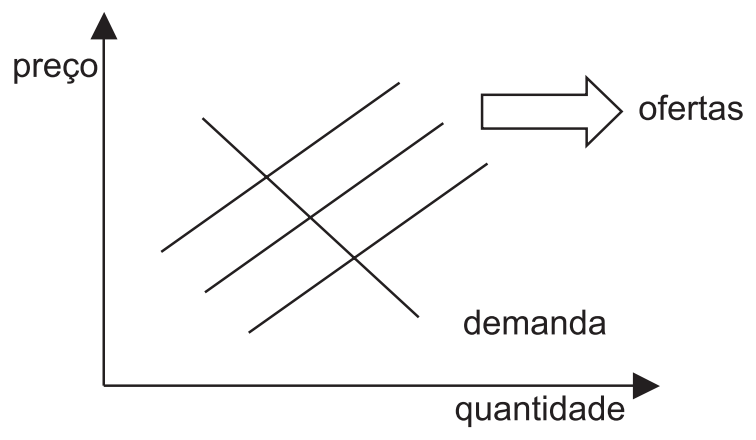

Fonte: Hayashi (2002, p. 190).

Em nosso caso específico, que variáveis poderíamos utilizar como instrumentos? A subseção anterior nos oferece algumas sugestões: (2) a renda agregada, (3) a inadimplência, (4) o prêmio de risco-país e (5) a taxa de juros internacional.

\subsection{Resultados}

De acordo com a descrição teórica do canal de crédito apresentada na seção 2.1, deveríamos esperar um coeficiente $\beta_{3}$ negativo na equação abaixo: quanto maior a taxa de juros, menor é o volume de crédito real.

2 De forma análoga, uma variável observável que deslocasse apenas a curva de demanda, e não a curva de oferta, poderia ser utilizada para se estimar a elasticidade-preço da oferta. 


$$
\text { cred_cres }=\beta_{0}+\beta_{1} \text { cred_cres }_{\mathrm{t}-1}+\beta_{2} \text { cred_cres }_{\mathrm{t}-2}+\beta_{3} \text { jurreal }_{\mathrm{t}-1}+\varepsilon_{\mathrm{t}}
$$

var. endógena: jurreal ${ }_{\mathrm{t}-1}$

var. instrumentais: inad ${ }_{t}$, inad ${ }_{t-1}$, inad $_{t-2}, \operatorname{prisc}_{t}, \operatorname{prisc}_{t-1}, \operatorname{prisc}_{t-2}$, fedfunds $_{t}$, fedfunds $s_{t-1}$, fedfunds $s_{t-2}$, pib $_{t}$, pib $_{t-1}$, pib $_{t-2}$

onde cred_cres é a taxa de crescimento t/t-4 do total de crédito (considerado de risco normal) do sistema financeiro privado ao setor privado em milhões de $\mathrm{R} \$$ a preços constantes do último trimestre de 2004; jurreal contém a taxa de juros real (selic deflacionada pelo IPCA); pib contém a taxa de crescimento do PIB em relação ao mesmo trimestre do ano anterior; a série inad mede a evolução no registro líquido (recebidos menos cancelados) de inadimplentes; cbond contém o spread em pontos-base do C-Bond sobre um título do Tesouro dos EUA; e fedfunds contém a taxa de juros dos fundos federais, que corresponde ao custo de reservas bancárias por um dia nos EUA.

A primeira coluna da Tabela 1 apresenta uma estimativa da equação por Mínimos Quadrados Ordinários (OLS). O resultado obtido é o de que a taxa de juros real não possui efeito algum sobre a demanda por crédito, dada a não-significância do coeficiente estimado. A segunda coluna da mesma tabela apresenta os resultado da estimação da mesma equação por meio do Método dos Momentos Generalizados (GMM), utilizando como variáveis instrumentais o valor corrente assim como a primeira e a segunda defasagens das seguintes variáveis: a inadimplência, o prêmio de risco, a taxa de juros americana e a taxa de crescimento do PIB. Note-se que com a utilização desses instrumentos o coeficiente estimado para a taxa de juros real é negativo e significativo. Para cada aumento de $1 \%$ na taxa de juros real trimestral, o volume de crédito real contrai-se em $0,533 \%$ com relação ao mesmo trimestre do ano anterior.

Visto que os coeficientes estimados via GMM são consistentes apenas se as variáveis instrumentais utilizadas forem exógenas, é valido discutir um pouco mais sobre a qualidade dos instrumentos utilizados. Apresentamos na seção 2.1 as razões teóricas pelas quais a renda, a inadimplência, o prêmio de risco e a taxa de juros internacional estariam relacionadas com a oferta de crédito. Porém, a hipótese de exogeneidade dos instrumentos requer que essas variáveis não afetem diretamente a demanda por crédito. A firma demanda crédito para financiar o estoque de capital que acredita ser o ótimo. O nível ótimo de capital é dado pela condição de que a produtividade marginal do capital seja igual à taxa de juros. Dessa forma, para que uma variável instrumental satisfaça a hipótese de exogeneidade, ela não pode afetar a produtividade marginal do capital.

Com relação à inadimplência e ao prêmio de risco-país (que pode ser visto como uma medida da probabilidade de inadimplência dos agentes domésticos com relação aos seus devedores externos), não há razões teóricas para se acreditar que ambas as variáveis afetam a produtividade marginal do capital. A princípio podemos dizer o mesmo para a taxa de juros internacional. Porém, algum desconforto com relação a essa variável pode ser gerado devido ao fato de ela representar o preço do crédito externo. Esse desconforto pode ser eliminado lembrando-se que o Brasil é um país "pequeno" em relação ao mercado financeiro internacional: enquanto a taxa de juros internacional afeta a oferta de crédito doméstico, é difícil aceitar a hipótese de que a demanda por crédito doméstico afeta a taxa de juros internacional. Por fim, outra variável potencialmente problemática é o nível de renda. Se, por um lado, podemos argumentar que o nível de renda não afeta diretamente a produtividade marginal do capital, por outro, pode-se argumentar que uma economia com um maior nível de renda possui um maior potencial consumidor, o que incentivaria as firmas a investirem mais. 
Tabela 1 - Variável dependente: crédito privado ao setor privado (taxa \% t/t-4 real)

Freqüência: trimestral

Período amostral: 1996.1 a 2002.4

Método de estimação

\begin{tabular}{|c|c|c|c|}
\hline & OLS & $\mathrm{GMM}^{1}$ & $\mathrm{GMM}^{2}$ \\
\hline \multicolumn{4}{|l|}{ Regressor } \\
\hline$\beta_{0}$ & $\begin{array}{c}0,021 \\
(0,032)\end{array}$ & $\begin{array}{c}0,036^{\star *} \\
(0,009)\end{array}$ & $\begin{array}{l}0,036^{\star *} \\
(0,011)\end{array}$ \\
\hline$\beta_{1}$ & $\begin{array}{c}1,149^{* *} \\
(0,228)\end{array}$ & $\begin{array}{c}1,415^{\star *} \\
(0,093)\end{array}$ & $\begin{array}{l}1,404^{* *} \\
(0,103)\end{array}$ \\
\hline$\beta_{2}$ & $\begin{array}{l}-0,448^{*} \\
(0,212)\end{array}$ & $\begin{array}{l}-0,725^{\star *} \\
(0,082)\end{array}$ & $\begin{array}{l}-0,733^{* *} \\
(0,086)\end{array}$ \\
\hline$\beta_{3}$ & $\begin{array}{l}-0,022 \\
(0,679) \\
\end{array}$ & $\begin{array}{l}-0,533^{*} \\
(0,219) \\
\end{array}$ & $\begin{array}{l}-0,483^{*} \\
(0,266)\end{array}$ \\
\hline \multicolumn{4}{|c|}{ Teste de sobre-identificação } \\
\hline Estatistica-J & & $\begin{array}{c}0,181 \\
(0,927)\end{array}$ & $\begin{array}{c}0,145 \\
(0,852)\end{array}$ \\
\hline \multicolumn{4}{|c|}{ Estatísticas descritivas } \\
\hline$S Q R$ & 0,022 & 0,125 & 0,125 \\
\hline $\mathrm{BIC}$ & $-3,047$ & & \\
\hline DPR & 0,045 & 0,072 & 0,072 \\
\hline $\mathrm{R}^{2}$ & 0,781 & & \\
\hline
\end{tabular}

Desvio padrão robusto a heteroscedasticidade e autocorrelação (Newey-West HAC) entre parênteses sob os coeficientes estimados por OLS e p-valor sob as estatísticas-J. Os símbolos * $\mathrm{e}^{* *}$ denotam que o coeficiente é significativo a $10 \%$ e $1 \%$, respectivamente.

SQR: soma quadrática dos resíduos.

BIC: critério de informação Bayesiano.

DPR: desvio padrão da regressão.

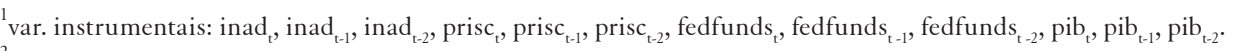

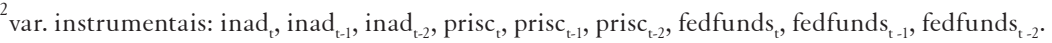

Sendo assim, reforçamos nossa confiança nas variáveis instrumentais utilizadas de duas formas. Em primeiro lugar, calculamos a estatística-J para a regressão efetuada via GMM. O método GMM escolhe os coeficientes de forma que os resíduos sejam ortogonais aos instrumentos utilizados. Quanto mais próximo de zero estiver a estatística-J, maior é a probabilidade de que esses instrumentos sejam ortogonais e, conseqüentemente, válidos. Este teste é conhecido como teste de sobre-identificação. Podemos notar pelo p-valor obtido que a hipótese de que a estatística-J apresentada na Tabela 1 não seja estatisticamente diferente de zero não é rejeitada a um nível de significância de 10\%. Em segundo lugar, reestimamos a Equação 1 via GMM retirando do conjunto de variáveis instrumentais o valor corrente e as 2 primeiras defasagens da taxa de crescimento do PIB. 
As estimativas obtidas são apresentadas na terceira coluna de resultados na Tabela 1, e revelam mudanças apenas marginais nos coeficientes: a elasticidade-juros da demanda por crédito vai de $-0,53$ a $-0,48$.

\section{IMPERFEIÇÕES DO CANAL DE CRÉDITO}

A exigência de garantias, ou colateral, resulta de uma imperfeição do mercado de crédito. O custo social desse procedimento fica claro quando um banco prefere financiar um indivíduo que queira abrir sua terceira firma, dado que este pode apresentar as outras duas como garantia, em vez de financiar um desempregado que queira montar sua primeira firma, mas que não possua garantias suficientes (mesmo que o projeto do desempregado possua um maior retorno e um menor risco esperados).

O objetivo desta seção é explorar conceitualmente a relação entre essa imperfeição no mercado de crédito e os choques sobre a demanda agregada. A primeira subseção discute como um problema de incentivo na relação credor-devedor gera essa imperfeição no mercado de crédito. E a segunda subseção descreve, de forma detalhada, como essa imperfeição atua como um "multiplicador financeiro" dos choques macroeconômicos, amplificando não apenas a magnitude, mas também a persistência dos efeitos de um choque temporário negativo.

\subsection{Problemas de incentivo e limites de crédito}

Em um mercado perfeito de crédito, a decisão relativa ao endividamento depende apenas dos retornos esperados dos investimentos. Investimentos produtivos seriam sempre financiados, e os preços dos ativos refletiriam apenas o que acontece no lado real da economia.

No entanto, diversos problemas de incentivos impedem que o mercado de crédito funcione de forma perfeita. Imperfeições no mercado de crédito podem decorrer de argumentos relacionados tanto a problemas de seleção adversa como de moral hazard. Ambas as teorias partem do pressuposto de que taxas de juros mais elevadas reduzem a participação das firmas no retorno do investimento realizado. Em estados da natureza em que as firmas são forçadas a pedir falência, o retorno destas não é alterado, pois firmas são protegidas por limited liability. No entanto, nos demais estados da natureza, o retorno líquido das firmas será reduzido. O argumento de moral hazard é que as firmas podem ser induzidas a buscar retornos mais arriscados, o que poderia levar a uma situação em que a probabilidade de pagamento das dívidas contraídas no banco seja reduzida. $\mathrm{O}$ argumento de seleção adversa é que quando os bancos não podem distinguir entre a qualidade das firmas, juros mais elevados tenderiam a eliminar do mercado as firmas com melhores projetos, pois firmas com projetos mais arriscados possuem elevada possibilidade de default e, portanto, não estariam sujeitas a variações nas taxas de juros (vide também Stiglitz-Weiss, 1981).

A solução, do ponto de vista do credor, é exigir do devedor o depósito de uma garantia de pagamento, ou colateral. Outra possibilidade é restringir o acesso ao crédito por parte do devedor, de tal forma que este deva, obrigatoriamente, utilizar parte de seu próprio capital para que o investimento seja realizado. As duas soluções exigem que uma fração do investimento total seja realizada com o capital próprio da firma, o que é o mesmo que financiar o projeto todo e exigir como colateral o depósito dessa fração. Procedendo desta forma, o credor poderá dividir com o devedor os custos de um resultado ruim do investimento realizado, incentivando, com isto, o devedor a ser mais cauteloso na escolha de seus projetos. 
É interessante notar, porém, que quando o mercado age dessa forma, o nível de investimento total passa a ser um múltiplo do que as firmas podem oferecer como colateral. De forma simplificada, as firmas podem oferecer (no máximo) como colateral todo o seu valor líquido, dado pelo seu balanço patrimonial. Assim, choques que afetem de maneira negativa o balanço das empresas, seja pelo lado do ativo (por exemplo, redução no nível de vendas, quedas nos preços de ativos que fazem parte do portfólio das empresas, etc), seja pelo lado do passivo (aumentos na taxa de juros, caso a empresa possua dívidas que paguem juros pós-fixados; ou desvalorizações cambiais, caso a empresa possua dívidas em dólar), podem fazer com que as firmas percam acesso a fundos necessários à realização do investimento. Isto significa que projetos lucrativos não são realizados. Existe, portanto, um feedback entre os preços dos ativos e o lado real da economia. Como veremos a seguir, esta interação explica como, por exemplo, choques puramente temporários de produtividade são responsáveis por grande persistência na dinâmica do nível de atividade. ${ }^{3}$

\subsection{Imperfeições no canal de crédito e demanda agregada}

Adotando-se uma perspectiva microeconômica, vamos supor que um choque positivo no preço de um ativo afete o valor presente de uma firma, seja porque este choque reduz o valor de um ativo, seja porque ele aumenta o valor de um passivo. Como vimos, a exigência de garantias pelo credor faz com que o limite de crédito de uma firma seja um múltiplo de seu valor líquido. Em um choque no sentido oposto, em firmas que estejam alavancadas até o seu limite de crédito o enfraquecimento de seu balanço patrimonial reduz o seu networth, reduzindo, assim, seu limite de crédito. Devido à necessidade de se ajustar a um limite de crédito inferior, a firma se vê obrigada a se desfazer de alguns ativos.

Quando as firmas que tiveram seu balanço patrimonial afetado negativamente se desfazem de novos ativos, a fim de se ajustarem a um novo limite de crédito, a redução na demanda por esses ativos produz uma queda em seus preços. A queda desses preços afeta o balanço patrimonial de outras firmas, reduzindo, então, seus respectivos limites de crédito. Este é o efeito multiplicador estático, pois ele "espalha", por outros setores, um choque de um setor específico, amplificando seus efeitos negativos. Note que se não houvesse a exigência de garantia, a primeira firma afetada não teria que se desfazer de ativos para se ajustar aos novos limites e, assim, não haveria este efeito multiplicador. Este, porém, não é o fim da história.

Quando a firma ajusta seu plano de investimento, para atender ao seu novo limite de crédito, ela está perdendo lucros futuros. A razão é simples: como o novo plano de investimento está associado a um volume de crédito menor, certamente ele poderia ter sido um dos escolhidos desde o princípio. Se não o foi é por estar necessariamente associado a um retorno menor do que o do plano de investimento inicialmente escolhido. Com uma expectativa de um lucro futuro menor, o valor líquido da firma (que é o valor presente de seus lucros futuros) volta a cair. Isto faz com que o seu volume de crédito (um múltiplo do seu valor líquido) se reduza novamente. Este segundo efeito é conhecido como multiplicador dinâmico, visto que ele estende o efeito de um choque em um determinado período, prolongando-o para períodos futuros.

A Figura 3 resume essas idéias. No período $t$, o multiplicador estático amplifica o efeito do choque no mesmo período. A necessidade da firma de reduzir suas posições aos novos limites de crédito causa uma nova queda nos preços dos ativos, trazendo um novo feedback negativo. No perí-

3 A literatura recente de ciclos econômicos tem enfatizado o papel do mercado de crédito como mecanismo de amplificação e propagação de choques na economia. (Bernanke e Gertler, 1995; e Kiyotaki e Moore, (1997). 
odo $t+1$, temos o multiplicador dinâmico, a venda de ativos e a redução nos planos de investimentos afetam os lucros esperados da firma, afetando novamente o seu valor presente.

Figura 3 - O multiplicador financeiro: efeitos estático e dinâmico

Período $\mathrm{t}$

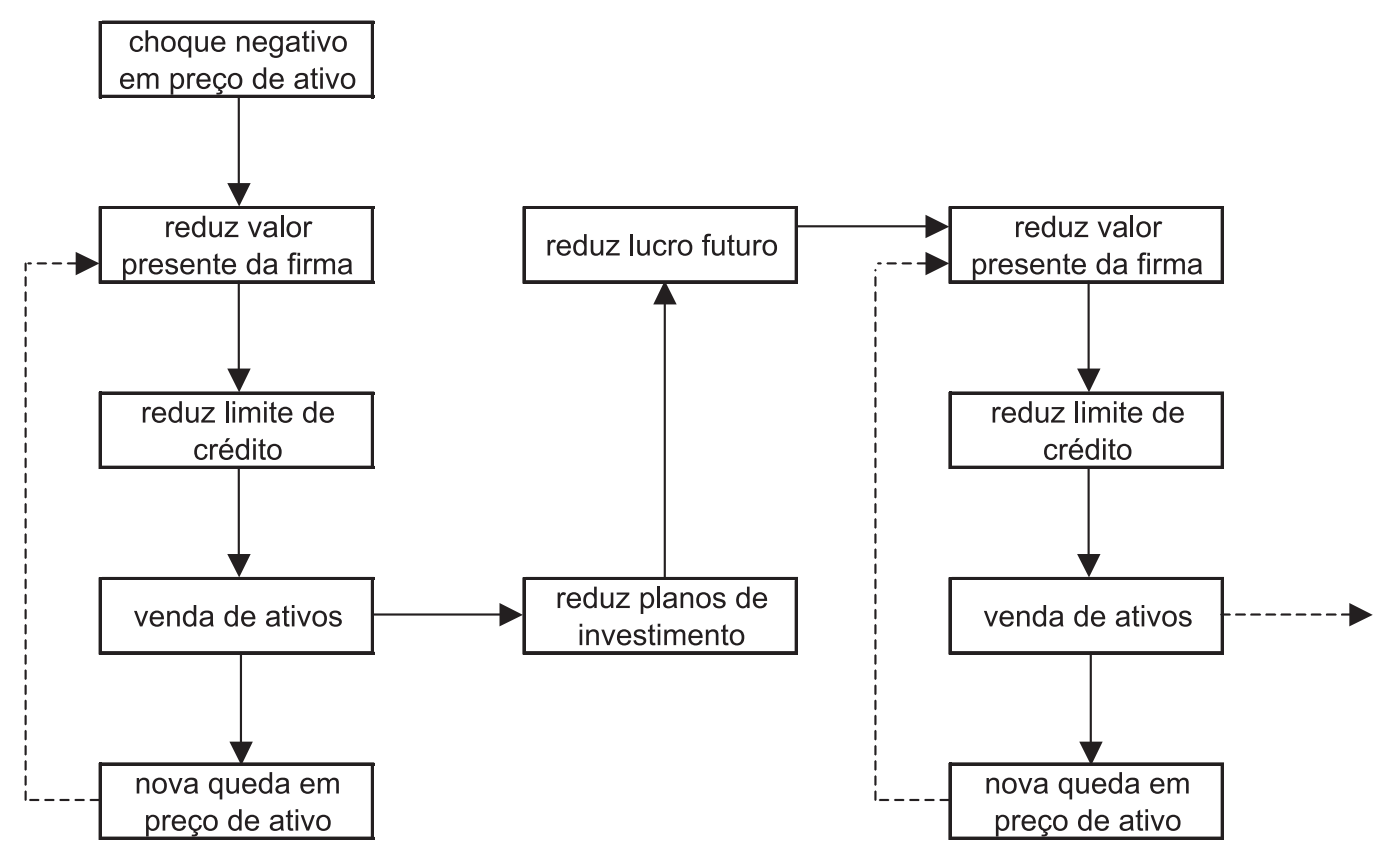

\subsection{Crédito e o papel da taxa de câmbio}

Na primeira seção deste artigo estimamos uma equação de demanda por crédito privado doméstico. Quando se aumenta a taxa de juros, o Banco Central eleva o custo de captação da firma, reduzindo sua capacidade de endividamento e, por esta via, suas possibilidades de fazer despesas de investimento. A Figura 4 deixa clara a relação entre o crescimento do crédito total ao setor privado e o crescimento do nível de investimento. Em seguida, apresentamos os mecanismos pelos quais as imperfeições no mercado de crédito podem fazer com que determinados preços de ativos afetem o nível de investimento, por meio de um enfraquecimento do "Balanço Patrimonial" das firmas. Visto que algumas firmas possuem dívida em moeda estrangeira, uma desvalorização cambial real aumenta o seu passivo, reduzindo o seu valor presente líquido, reduzindo, assim, seu limite de crédito. Para uma firma cujo limite de crédito esteja ativo, isto significa que o seu nível de investimento deve se ajustar ao novo limite de crédito.

Nesta seção estamos interessados em obter evidência empírica da atuação deste multiplicador financeiro na economia brasileira, por meio de movimentos da taxa de câmbio. Em economias parcialmente dolarizadas, ou com moeda "fraca", na medida em que diversas firmas possuem passivo em dólar, uma depreciação (justificada ou não pelos fundamentos econômicos) na taxa de câmbio

4 A amplificação de choques causada por modificações nas condições de crédito é denominada acelerador financeiro (financial accelerator) pela literatura. (Bernanke, Gertler e Gilchrist, 1996). 
eleva o passivo dessas empresas, enfraquecendo seus balanços, afetando o crédito, o investimento e a demanda agregada.

A fim de testar a hipótese de que a taxa de câmbio afeta a capacidade de endividamento da firma, reestimamos a equação de demanda por crédito, incluindo, desta vez, a desvalorização cambial real como variável explicativa. ${ }^{5}$ Dois pontos importantes devem ser ressaltados com relação à interpretação e à própria execução desse procedimento.

Figura 4 - Crédito e investimento (taxas de crescimento) - \%

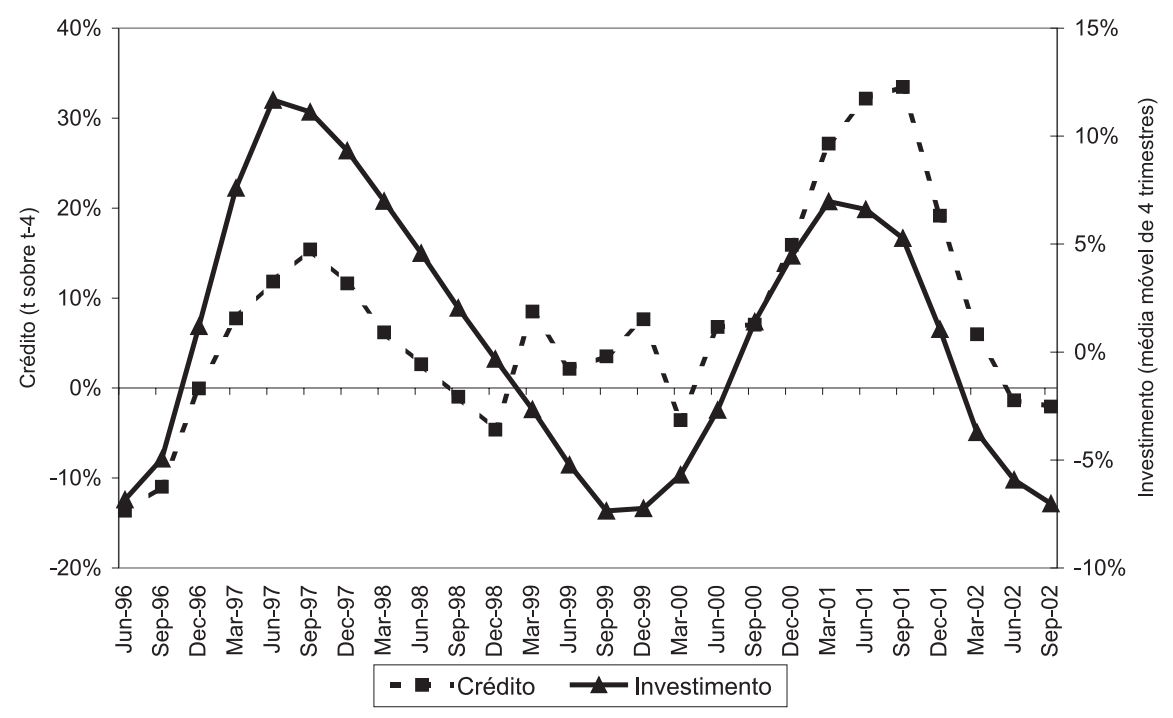

Fonte: IBGE e Banco Central do Brasil.

Em primeiro lugar, deve estar claro que se a taxa de câmbio afeta o limite de crédito de uma firma, este efeito deve ser captado na equação de demanda, e não na de oferta por crédito. Uma forma intuitiva de entender o motivo é estabelecer um paralelo entre a demanda por crédito e a demanda por um bem qualquer. Pensando no modelo microeconômico mais simples, a demanda por um bem qualquer é função negativa de seu preço e positiva da riqueza (dotação inicial) que o consumidor possui para compor sua cesta de bens. No caso do mercado de crédito, já vimos que a taxa de juros real representa o "preço" do crédito. No caso de mercados imperfeitos, que exigem colaterais como garantia, o valor presente da firma é a dotação que ela possui para "comprar" crédito. Dessa forma, como a taxa de câmbio afeta negativamente o valor presente da firma (por meio do seu passivo em moeda estrangeira), devemos esperar que a equação de demanda por crédito mostre um coeficiente negativo entre o crédito e a taxa de câmbio.

Em segundo lugar, devemos nos assegurar de que este coeficiente não esteja captando movimentos via oferta de crédito. Apesar de nossa variável dependente ser o crédito total do setor privado doméstico, conforme já discutimos na seção anterior, uma instituição financeira doméstica pode estar captando recursos externos e os repassando no mercado doméstico. Neste caso, movimentos na taxa de câmbio podem estar afetando, diretamente, a disponibilidade desses recursos externos e,

5 Dessa forma, estamos estimando a elasticidade-câmbio da demanda por crédito agregada. Bonomo, Martins e Pinto (2003) apresentam evidência empírica do efeito da taxa de câmbio no investimento das firmas brasileiras via "Balanço Patrimonial" usando dados desagregados. 
indiretamente, a oferta de crédito doméstica. ${ }^{6}$ Mais uma vez, não sabemos se o coeficiente estimado para a taxa de câmbio estará captando esta influência por meio da oferta de recursos externos ou via limites de demanda por crédito.

Fazemos uso, então, de variáveis instrumentais para a desvalorização cambial real (além daquelas já utilizadas para a taxa de juros real). Estas variáveis devem estar relacionadas ao efeito do câmbio, via oferta de crédito externo, a fim de garantir que o coeficiente estimado esteja associado a movimentos de demanda por crédito interno. As variáveis que utilizamos foram obtidas decompondo-se a taxa paga pelo C-Bond em uma medida de prêmio de risco e em uma medida da taxa de juros internacional. A escolha destas variáveis se deve ao fato de estas estarem, tipicamente, associadas a equações de paridade da taxa de juros. Estas refletem diretamente a propensão do investidor externo em investir em títulos de renda fixa no Brasil, afetando diretamente a oferta de crédito externo no mercado interno.

cred_cres $_{t}=\beta_{0}+\beta_{1}$ cred_cres $_{\mathrm{t}-1}+\beta_{2}$ cred_cres $_{\mathrm{t}-2}+\beta_{3}$ jurreal $_{\mathrm{t}-1}+\beta_{4} \Delta$ cambio $_{\mathrm{t}-1}+\varepsilon_{\mathrm{t}}$

var. endógenas: jurreal ${ }_{\mathrm{t}-1}, \Delta$ cambio $_{\mathrm{t}-1}$

var. instrumentais: inad ${ }_{t}$, inad $d_{t-1}$, inad $_{t-2}, \operatorname{prisc}_{t}, \operatorname{prisc}_{t-1}, \operatorname{prisc}_{t-2}$, fedfunds $s_{t}$, fedfunds $t-1$, fedfunds $t_{t-2}$, pib $_{t}$, $\mathrm{pib}_{\mathrm{t}-1}, \mathrm{pib}_{\mathrm{t}-2}$

onde cred_cres, jurreal, pib, inad, cbond e fedfunds possuem as mesmas definições da seção 2.3 e a série $\Delta$ cambio contém a taxa de depreciação do câmbio nominal.

A primeira coluna de resultados da Tabela 2 apresenta uma estimativa da equação por Mínimos Quadrados Ordinários (OLS). Da mesma forma que na seção 2.3, o coeficiente associado à taxa de juros real não é significativo na regressão via OLS. Com relação ao coeficiente associado à taxa de depreciação cambial, este coeficiente é negativo e significativo. A segunda coluna de resultados da mesma tabela apresenta os resultados da estimação da mesma equação via Método dos Momentos Generalizados (GMM), utilizando como variáveis instrumentais a primeira e a segunda defasagens da taxa de crescimento do PIB e da inadimplência para a taxa de juros real e a primeira e segunda defasagens do prêmio de risco e da taxa de juros dos EUA para a taxa de depreciação cambial.

Por meio do GMM, o coeficiente associado à taxa de juros real passa ser negativo e significativo a menos de $1 \%$ : um aumento de $1 \%$ na taxa de juros real trimestral encolhe em $0,5 \%$ o volume real de crédito em relação ao mesmo trimestre do ano anterior. O coeficiente obtido para a taxa de depreciação cambial também é negativo e significativo a menos de $1 \%$ : para cada $1 \%$ que a taxa de câmbio se deprecia, o volume de crédito real cai em $0,23 \%$ com relação ao mesmo trimestre do ano anterior. $\mathrm{O}$ interessante é notar que o coeficiente obtido para a taxa de depreciação cambial via GMM é próximo ao coeficiente obtido via OLS em termos de magnitude, sendo ambos significativos a menos de $1 \%$. Isso sugere que o problema de endogeneidade com relação à taxa de depreciação cambial não é tão grave assim. Podemos notar ainda pelo p-valor obtido na Tabela 2 que a estatística-J obtida para a equação estimada via GMM não é significativamente diferente de zero. Isto é uma evidência empírica a favor da hipótese de que os instrumentos sejam ortogonais e, conseqüentemente, válidos.

6 Em Carneiro e Wu (2002) apresentamos evidência empírica de que movimentos da taxa de câmbio afetam o nível de reservas internacionais, por meio de uma racionalidade via Paridade da Taxa de Juros. 
Tabela 2 - Variável dependente: crédito privado ao setor privado (taxa \% t/t-4 real)

Freqüência: trimestral

Período amostral: 1996.1 a 2002.4

\section{Método de estimação}

\begin{tabular}{|c|c|c|c|}
\hline & OLS & $\mathrm{GMM}^{1}$ & GMM $^{2}$ \\
\hline \multicolumn{4}{|l|}{ Regressor } \\
\hline$\beta_{0}$ & $\begin{array}{c}0,032 \\
(0,030)\end{array}$ & $\begin{array}{l}0,048^{* *} \\
(0,009)\end{array}$ & $\begin{array}{c}0,047^{\star *} \\
(0,021)\end{array}$ \\
\hline$\beta_{1}$ & $\begin{array}{c}1,336^{* *} \\
(0,202)\end{array}$ & $\begin{array}{l}1,264^{* *} \\
(0,118)\end{array}$ & $\begin{array}{c}1,446^{* *} \\
(0,144)\end{array}$ \\
\hline$\beta_{2}$ & $\begin{array}{l}-0,623^{\star *} \\
(0,178)\end{array}$ & $\begin{array}{l}-0,690^{* *} \\
(0,069)\end{array}$ & $\begin{array}{l}-0,747^{\text {** }} \\
(0,103)\end{array}$ \\
\hline$\beta_{3}$ & $\begin{array}{c}0,059 \\
(0,749)\end{array}$ & $\begin{array}{l}-0,491^{* *} \\
(0,218)\end{array}$ & $\begin{array}{l}-0,683^{\star *} \\
(0,388)\end{array}$ \\
\hline$\beta_{4}$ & $\begin{array}{l}-0,299^{* *} \\
(0,051)\end{array}$ & $\begin{array}{l}-0,234^{* *} \\
(0,027) \\
\end{array}$ & $\begin{array}{l}-0,249^{* *} \\
(0,043)\end{array}$ \\
\hline \multicolumn{4}{|c|}{ Teste de sobre-identificação } \\
\hline Estatistica-J & & $\begin{array}{c}0,168 \\
(0,909) \\
\end{array}$ & $\begin{array}{c}0,135 \\
(0,806) \\
\end{array}$ \\
\hline \multicolumn{4}{|c|}{ Estatísticas descritivas } \\
\hline SQR & 0,088 & 0,098 & 0,101 \\
\hline $\mathrm{BIC}$ & $-2,331$ & & \\
\hline DPR & 0,062 & 0,065 & 0,066 \\
\hline $\mathrm{R}^{2}$ & 0,772 & & \\
\hline
\end{tabular}

Desvio padrão robusto a heteroscedasticidade e autocorrelação (Newey-West HAC) entre parênteses sob os coeficientes estimados por OLS e p-valor sob as estatísticas-J. Os símbolos * $\mathrm{e}^{* *}$ denotam que o coeficiente é significativo a $10 \%$ e $1 \%$ respectivamente.

SQR: soma quadrática dos resíduos.

BIC: critério de informação Bayesiano.

DPR: desvio padrão da regressão.

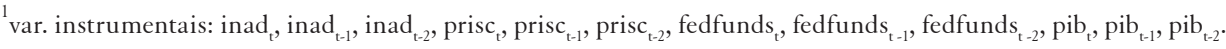

${ }^{2}$ var. instrumentais: inad ${ }_{t}$, inad $_{t-1}$, inad $_{t-2}$, prisc $_{t}$, prisc $_{t-1}$, prisc $_{t-2}$, fedfunds $s_{t}$, fedfunds $s_{t-1}$, fedfunds $s_{t-2}$.

Por fim, pelas mesmas razões mencionadas na seção 2.3, reestimamos a Equação 2 via GMM, retirando a taxa de crescimento do PIB da lista de variáveis instrumentais. As novas estimativas obtidas, apresentadas na terceira e última coluna de resultados, são muito próximas dos valores obtidos por meio da regressão GMM original. 


\section{CONCLUSÃO}

Neste artigo analisamos o papel do crédito como mecanismo de transmissão da política monetária. Em seguida, enfocamos o canal de crédito como transmissor dos choques de demanda, via balanço das empresas, atuando como um "multiplicador financeiro" desses choques. Por fim, apresentamos evidência empírica acerca da atuação deste "multiplicador financeiro" na economia brasileira via movimentos da taxa de câmbio.

A questão referente ao canal de crédito como transmissor dos impulsos da política monetária foi tratada por meio da estimativa dos efeitos de um aumento na taxa de juros sobre a demanda por crédito pela qual firmas financiam seus investimentos, um dos principais componentes da demanda agregada. Um aumento na taxa de juros reduz a capacidade de as firmas se endividarem, diminuindo o número de projetos de investimentos que são efetivamente financiados e realizados. Os resultados sugerem que a elevação de juros é eficaz para provocar uma queda no nível de atividade, via redução na demanda por crédito e, conseqüentemente, no nível de investimento. Estimamos que para cada $1 \%$ de aumento na taxa de juros real o total de crédito demandado cai em, aproximadamente, $0,5 \%$.

Mais importante que a estimação do canal de crédito, em si, é a forma como as imperfeições típicas do mercado de crédito ajudam a propagar e amplificar certos choques temporários. Neste artigo, ainda exploramos conceitualmente a relação entre imperfeições no mercado de crédito e choques sobre a demanda agregada. A exigência de garantias, ou colateral, resulta de uma imperfeição do mercado de crédito. Em certas situações (estados da natureza), o resultado do investimento realizado pode vir a ser tão ruim que não há possibilidade de pagamento. Do ponto de vista do patrimônio do devedor, se ele investiu e perdeu apenas o capital do credor, então não houve nenhum efeito no seu balanço. Isto gera um incentivo perverso ao devedor no sentido de este se preocupar menos com as possibilidades de perda e de assumir riscos mais elevados quando não arrisca seu próprio patrimônio. A solução, do ponto de vista do credor, é exigir do devedor o depósito de uma garantia de pagamento, ou colateral.

É interessante notar, porém, que quando o mercado age dessa forma, o nível de investimento total passa a ser um múltiplo do que as firmas podem oferecer como colateral. De forma simplificada, as firmas podem oferecer como colateral no máximo todo o seu valor líquido, dado pelo seu balanço patrimonial. Assim, choques que afetem, de maneira negativa, o balanço das empresas, seja pelo lado do ativo (por exemplo, redução no nível de vendas, quedas nos preços dos ativos que fazem parte do portfólio das empresas etc.), seja pelo lado do passivo (aumentos na taxa de juros, caso a empresa possua dívidas que paguem juros pós-fixados, ou desvalorizações cambiais, caso a empresa possua dívidas em dólar), podem fazer com que as firmas percam acesso a fundos necessários à realização do investimento. Ou seja, essa imperfeição no mercado de crédito funciona como um "multiplicador financeiro" de choques sobre a demanda agregada.

Por fim, ilustramos a atuação deste "multiplicador financeiro" na economia brasileira. Testamos a hipótese de que a taxa de câmbio afeta a capacidade da firma de se endividar, na medida em que uma desvalorização cambial real eleva o valor do passivo em moeda estrangeira de uma firma, reduzindo seu valor líquido presente, que é uma proxy do que a firma pode apresentar como colateral para um empréstimo. Ao reestimarmos a equação de demanda por crédito, incluindo a desvalorização cambial real como variável explicativa, obtivemos um coeficiente negativo e significativo. Utilizando variáveis instrumentais que expurgam os efeitos da taxa de câmbio sobre o crédito, via oferta de recursos externos, concluímos que uma desvalorização cambial de $1 \%$ reduz a capacidade de a firma se endividar em $0,25 \%$. 


\section{REFERÊNCIAS BIBLIOGRÁFICAS}

Bernanke, B. S.; Gertler, M.; Gilchrist, S. The financial accelerator and the flight to quality. Review of Economics and Statistics, v. 78, n. 1, p. 1-15, Fev. 1996.

Bonomo, M.; Martins, B.; Pinto, R. Debt composition and exchange rate balance sheet effect in Brazil: a firm level analysis. Emerging Markets Review, v. 4, n. 4, p. 368-396, 2003.

Carneiro, D. D.; Wu, T. A restrição externa ao crescimento. Carta Econômica Galanto, Jan. 2001.

. Câmbio, juros e o movimento de reservas: faz sentido o uso de um 'quebra-molas'? Texto para Discussão, PUC-Rio, n. 459, 2003.

Friedman, M. A theory of the consumption function. Princeton University Press, 1957.

Hayashi, F. Econometrics. Princeton University Press, 2002.

Kiyotaki, N.; Moore, J. Credit cycles. Journal of Political Economy, v. 105, n. 2, p. 211-248, Abr. 1997.

Modigliani, F.; Brumberg, R. Utility analysis and the consumption function: an interpretation of cross-section data. In: Kurihara, K. K (ed.), Post-Keynesian economics. New Brunswick, NJ: Rutgers University Press, 1954.

Stiglitz, J. E.; Weiss, A. Credit rationing in markets with imperfect information. American Economic Review, v. 71, n. 3, p. 393-410, Jun. 1981.

Taylor, J. The monetary transmission mechanism: an empirical framework. Journal of Economic Perspectives, n. 9, p. 27-48, Outono 1995.

\section{APÊNDICE}

Neste apêndice apresentaremos uma análise mais detalhada de como problemas de incentivo podem gerar contrações de crédito e investimento na economia. Em particular, mostraremos como uma redução do balanço patrimonial das firmas pode intensificar o problema de moral hazard, de modo que oportunidades de investimento produtivas deixem de ser realizadas.

O modelo apresentado a seguir baseia-se no artigo de Stiglitz e Weiss (1981). Considere uma firma que deve escolher entre dois tipos de projetos a serem levados a cabo. O primeiro, que denotaremos tipo $\mathrm{A}$, gera um pay off $\mathrm{P}$ (medido em reais) com probabilidade $\mathrm{p}_{\mathrm{a}}$, e zero com probabilidade $1-\mathrm{p}_{\mathrm{a}}$. O segundo, denominado tipo $\mathrm{B}$, gera o mesmo pay off $\mathrm{P}$ com probabilidade $\mathrm{p}_{\mathrm{b}}$, e zero com probabilidade $\left(1-\mathrm{p}_{\mathrm{b}}\right)$. Iremos supor que o projeto A é mais arriscado, ou seja, $\mathrm{p}_{\mathrm{a}}<\mathrm{p}_{\mathrm{b}}$. Por simplicidade, para levar a cabo qualquer um dos dois projetos é necessário incorrer em um investimento de I reais. Para motivar a necessidade de crédito na economia, suporemos que o balanço patrimonial da firma $(\mathrm{N})$ é menor que o investimento necessário para tocar os projetos, ou seja, $\mathrm{N}<\mathrm{I}$. Desta forma, a firma poderá levar o projeto adiante apenas se conseguir um empréstimo de (I-N) reais. Caso a firma não consiga obter crédito, as oportunidades de investimento dos projetos A e B serão perdidas.

Para tornar o problema interessante, suponha que o projeto A gera, para a firma, benefícios privados (não monetários) F, independentemente do estado da natureza. Por fim, iremos admitir que as seguintes desigualdades sejam válidas:

$$
\mathrm{p}_{\mathrm{a}} \mathrm{P}+\mathrm{F}<\mathrm{I}<\mathrm{p}_{\mathrm{b}} \mathrm{P}
$$

Mostraremos agora que, em equilíbrio, o investimento tipo A nunca será levado a cabo. Considere um banco que deva escolher entre emprestar à firma ou emprestar à taxa de juros sem risco 
(que será normalizada para zero, por simplicidade). A firma promete ao banco um pay off $\mathrm{R}_{a}$, caso o investimento seja bem-sucedido. Para que o banco empreste à firma é preciso que o retorno esperado seja o mesmo que o retorno da taxa de juros sem risco, ou seja, é preciso que:

$$
\mathrm{p}_{\mathrm{a}} \mathrm{R}_{\mathrm{a}}=\mathrm{I}-\mathrm{N}
$$

O pay off líquido esperado da firma caso ela invista no projeto A é igual ao pay off esperado menos o pagamento esperado realizado ao banco:

$$
\mathrm{p}_{\mathrm{a}} \mathrm{P}+\mathrm{F}-\mathrm{p}_{\mathrm{a}} \mathrm{R}_{\mathrm{a}}
$$

Substituindo a equação (2) na equação (3) e, por fim, utilizando a primeira desigualdade da equação (1), temos que o pay off líquido da firma é igual a:

$$
\mathrm{p}_{\mathrm{a}} \mathrm{P}+\mathrm{F}-\mathrm{I}+\mathrm{N}<\mathrm{N}
$$

A equação (4) mostra que não é vantajoso para a firma investir no projeto A, pois o pay off líquido esperado é menor do que o balanço patrimonial da firma.

Repetindo os mesmos passos acima, é fácil mostrar que caso a firma tenha acesso a crédito, vale a pena investir no projeto $\mathrm{B}$, pois o pay off líquido esperado deste projeto é superior ao balanço patrimonial da firma:

$$
\mathrm{p}_{\mathrm{b}} \mathrm{P}-\mathrm{I}+\mathrm{N}>\mathrm{N}
$$

Suponhamos que o mercado de crédito funcione de modo que o banco não possa influenciar a escolha dos projetos. Isto é, uma vez que o banco tenha emprestado recursos à firma, a decisão sobre qual projeto será levado a cabo dependerá exclusivamente da última.

Se isso for verdade, o banco só irá liberar os recursos à firma sob duas condições. A primeira é que o retorno esperado do empréstimo à firma seja igual ao retorno proporcionado pela taxa de juros sem risco:

$$
\mathrm{p}_{\mathrm{b}} \mathrm{R}=\mathrm{I}-\mathrm{N}
$$

Onde R e o pay off prometido pela firma ao banco, caso o projeto seja bem-sucedido. A segunda é que o banco se certifique de que a firma irá escolher pelo projeto tipo B. Em outras palavras, é preciso que o pay off líquido da firma no caso da escolha pelo projeto B seja maior que no caso da escolha pelo projeto tipo A:

$$
\left(\mathrm{p}_{\mathrm{b}}-\mathrm{p}_{\mathrm{a}}\right)(\mathrm{P}-\mathrm{R})>\mathrm{F}
$$

Combinando as equações (6) e (7), é possível mostrar que a firma só obterá crédito bancário se:

$$
N>p_{b} F /\left(p_{b}-p_{a}\right)-\left(p_{b} P-I\right)
$$

Ou seja, apenas firmas com balanço patrimonial acima de um determinado nível obterão empréstimos do banco.

Podemos agora fazer uma interessante aplicação ao caso brasileiro. O balanço patrimonial de uma firma pode ser definido como a diferença entre os ativos $(\mathrm{H})$ e o passivo. Uma das razões 
pelas quais uma desvalorização cambial afeta o crédito na economia é que em geral várias firmas possuem passivos em dólar. Desta forma, para analisar o impacto de uma desvalorização cambial na oferta de crédito iremos supor, por simplicidade, que o passivo da firma esteja todo em dólar (L), e o ativo todo em reais. O balanço patrimonial da firma em reais é, portanto, igual a:

$$
\mathrm{N}=\mathrm{H}-\mathrm{EL}
$$

Onde E é a taxa de câmbio nominal. Substituindo a equação (9) na equação (8) temos que a firma só obterá crédito caso a taxa de câmbio não ultrapasse um certo valor, ou seja, se:

$$
\mathrm{E}<\left[\mathrm{H}-\mathrm{p}_{\mathrm{b}} \mathrm{F} /\left(\mathrm{p}_{\mathrm{b}}-\mathrm{p}_{\mathrm{a}}\right)+\left(\mathrm{p}_{\mathrm{b}} \mathrm{R}-\mathrm{I}\right)\right] / \mathrm{L}
$$

A equação (10) mostra que quando as firmas possuem passivos em dólar que não possuem hedge, uma desvalorização cambial irá reduzir o balanço patrimonial das firmas e, com isto, a oferta de crédito será limitada. Isto, por sua vez, irá impactar o nível de atividade por meio da redução do investimento das firmas. 